WSRC-TR- $-91-381$

DE92 009645

\title{
WSRC-WASTE AND ENVIRONMENTAL ANALYTICAL METHODS (U)
}

by

\section{W. A. Spencer}

Westinghouse Savannah River Company

Savannah River Site

Aiken, South Carolina 29808

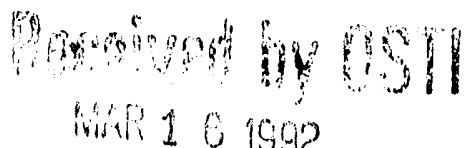

A Technical Report for publication on

July 12,1991

This paper was prepared in connection with work done under Contract No. DE-AC09-89SR18035 with the U.S. Department of Energy. By acceptance of this paper, the publisher and/or recipient acknowledges the U.S. Government's right to retain a nonexclusive, royalty-free license in and to any copyright covering this paper, along with the right to reproduce and to authorize others to reproduce all or part of the copyrighted paper. 
Keywords:

analytical methods waste characterization environmental analyses

Retention Period: Permanent

May 22, 1991

To: J.L. Steele, WSRC, OTD Technical Program Manager

From: W.A. Spencer

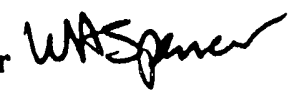

\section{WSRC Waste and Environmental Analytical Methods (U)}

WSRC uses 491 analytical procedures to directly support waste and environmental analytical work. A list of WSRC analytical methods is attached. The list is available from the author as a lotus or excel spreadsheet file. Copies of the actual procedures may be obtained by onsite jersonnel through the procedure coordinators for each laboratory. Procedures may also be obtained from the WSRC Information Services Section. Offsite personnel should request procedures through the DOE-SR Waste Management Technology Branch.

Procedures primarily used for production support are not included in the list. WSRC maintains approximately 1000 analytical procedures for production support. The production procedures compliment the waste and environmental procedures. For example, most reagent preparations and many administrative procedures are provided in the production support analytical procedures. Procedures for facility operations, QA, accountability, safety, HP, property, and other management controls are not listed except if they specifically dealt with waste handling. Many of these other procedures cover basic lab services, building equipment, and systems that would be necessary to safely operate a laboratory. A comprehensive overview of WSRC procedures system can be obtained through the WSRC Management Integration Section.

The WM/EM procedures were sorted accorting to the following categories:

$\begin{array}{lll}\text { Abbreviation } & \text { TYPE } & \text { NUMBER } \\ \text { adm } & \text { administrative } & 30 \\ \text { em } & \text { environmental monitoring } & 100 \\ \text { eps } & \text { environmental process support } & 28 \\ \text { erd } & \text { environmental R\&D } & 23 \\ \text { wch } & \text { waste characterization } & 67 \\ \text { wpk } & \text { waste packaging - lab wastes } & 22 \\ \text { wps } & \text { waste process support } & 125 \\ \text { wrd } & \text { waste R\&D } & 96\end{array}$

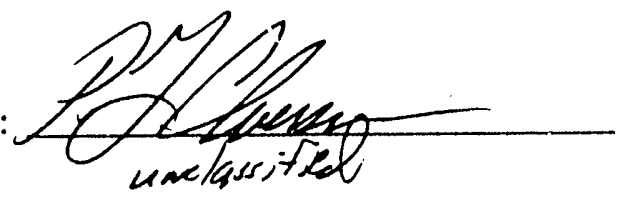


The data was sub-sorted by work group. The group indicates the primary WSRC user group. Because WSRC lab groups divide along process or environmental material lines, the group indicates whether the procedure is being used in a facility suitable for radioactive samples. The groups are identified below. The group indicates the mostly likely type of sample, high activity alpha (grams of $\mathrm{Pu}$ ), beta or tritium (few curies/liter), or high gamma materials (needing shielded cells). For example SRL (-IWT,-DWFT, ADS), DWPF, and the AL-Separations process labs all have access to high activity shielded cells. SRLADS and AL-Separations labs have glovebox access. Almost all ADS, DWPF, and AL labs have analytical instruments which are contained to measure radioactive materials where as most environmental labs have instruments suitable for only trace levels of radioactivity.

\begin{tabular}{ll} 
Abbreviation & Group \\
\hline AL 772D & Process Labs- AL Darea
\end{tabular}

AL Prod Process Labs - AL Separations

$A L Q C$

AL ETF ALF-ALL ALF-APA ALF-ENG ALF-SPC ALF-PIL AL-Marea DWPF EM SRL-ADS

SRL-ETS

SRL-IWTS

SRL-DWPT
Process Lab- AL QC

Process Lab - Effluent Treatment

Process Lab - AL general

Process Lab - AL Accountability

Process Lab - AL Lab Support

Process Lab - Sep. Process Control

Process Lab - Process Instrumentation

Process Lab - AL Fuel Fabrication

Process Lab -Defense Waste Process

Environmental Monitoring

SRL - Analytical Development

SRL - Environmental Technology

SRL - Interim Waste Technology

SRL - DW Glass Technology(773A)

SRL - DW Process Technology(TNX)
Primary Materials

Heavy Water $w /$ Tritium

Process Water Systems

Reactor Non-rad

Actinide Production,

High Alpha Samples

Some High Gamma

Moderate Tritium

$P E$ and $Q C$ samples

Low Beta Gamma

High Alpha Samples

Lab Waste \& Materials

High Gamma, Alpha

High Alpha

High U, Effluent

High Gamma

Little to no activity

Mixed R\&D

High Gamma

High Alpha

Moderate Tritium

Little to no activity

Ultratrace \& Low Activity

Mixed R\&D

High Activity Waste

Contaminated Materials

High Gamma R\&D

Non-rad Process R\&D

Many of the laboratories use similar procedures. In general a waste analysis procedure will first appear in the SRL,-ADS group as an R\&D procedure for both radioactive and non-radioactive samples. The

procedure will be transferred to the SRL-DWPT group at TNX as a non-radioactive method. At TNX the procedure is modified to work in a process environment instead of an R\&D one. The TNX lab must make the method efficient enough to support process time commitments. The final waste analyses procedure will be transferred to an AL or DWPF process laboratory where the lessons learned from the both the SRL R\&D laboratory and the SRL Pilot operations are combined. The process laboratories primarily work with radioactive samples after "cold" test runs. DWPF laboratory is presently in the "cold" non-radioactive test phase of startup.

The details in a procedure tends to improve as a procedure moves from the R\&D laboratory towards the process laboratory. For example in the R\&D laboratory general use procedures allowing for many types 
of matrices dominate where as in the process labs procedures tend to be specific for the process stream being analyzed.

An additive to process laboratory procedures will be the availability of lesson plans. Both the DWPF and the AL process control laboratories are required to follow the DOE 5480.18 order on accreditation and training of nuclear workers. These laboratories are actively identifying the key elements in their procedures and have already developed full comprehensive lesson plans and training programs to qualify technicians to preform many of the operations in the procedures. The R\&D laboratories expect to have some of their technicians fall under the accreditation order. In these instances the R\&D laboratories expect to follow the systems developed in the process control laboratories.

All of the WSRC laboratories place a major emphasis on QC programs. The process and environmental laboratories have full blind and double blind standards programs to verify that procedures and technicians are performing as expected. The R\&D labs stress that controls must be added by the customer and have a simpler check standard requirement on use of procedures. Many of the procedures describing the $Q C$ programs are covered under the QA, production, and accountability procedures and were not identified in the attached list.

The Environmental Monitoring laboratories primarily follow the DOE order 5400.6 for environmental measurements and have not developed lesson plans for procedures at this time. Their procedures follow EPA and DOE-EMSL guidelines and tend to be performance based. The EM procedures are used to monitor the work of offsite contracted laboratories and follow state and EPA required analyses protocols. The "Interim" status of the EM procedures reflects that these procedures are being rewritten to comply with a new procedures format specified by WSRC. The actual procedure on hand follows the previous contractor's [DuPont] format. EM expects to have all procedures converted by fall of ' 91 . Other site laboratories have converted their procedures to the newer formats. Most of the EM radiolytic methods are site versions of the HASL methods.

The SRL-ADS R\&D analytical support laboratory is primarily designed for flexibility. This group will set up and use any of the other plant laboratory procedures as needed to backup plant operations. This group will readily use standard procedures developed by recognized offsite committees such as ASTM procedures and those in "Standard Methods for Waste and Water Analyses". Some adaptation is needed to adjust for different instrumentation.

For the most part all of the laboratories tend to have the same equipment. For example Canberra counting systems, HP GCs, and Dionex IC systems are common to R\&D and process labs. .

The SRL- ADS procedures are unique in that the individual procedures contain sections on training requirements and $\mathrm{QC}$. Where as the process laboratories have extemal procedures covering training and QC requirements. A feature of many of the SRL-ADS procedures is that the training requirements are tiered to the functions of the user. For example a backup or overtime operator might be qualified to only run the instrument with preset conditions whereas the primary operator may, with special training that is described in the procedure, change the instrument conditions. Many ADS methods require testing and evaluation before use but the systems are not as formal as the process laboratories, at present.

A large number of waste characterization procedures were written as site clones of EPA procedures. This was done to have specific procedures on hand for local equipment and meet EPA guidelines for good laboratory practise. Many of the "EPA" procedures in the SRL-ADS group have had only limited testing on radioactive materials at this time. However this is an area of active research and all of the methods are expected to be fully checked out during the next three years.

The DWPF analytical procedures are designed to be used in highly radioactive environment. However the DWPF facility, which is the high activity glass vitrification facility, has not handled radioactive material at this time. The procedures are being thoroughly tested in cold runs using the hot cells and synthetic 
samples. All of the DWPF procedures were run on radioactive R\&D materials in SRL and are used as process support samples at TNX. Actual radioactive samples are expected in the next three years when DWPF starts processing real waste. The "DRAFT" status of a DWPF procedures indicates that the laboratory has a recoinmended procedure from SRL or has developed one themselves but that the procedure has not been accepted for process control use during startup runs.

The SRL - ETS procedures are primarily used to determine native backgrounds of non-contaminated areas. These analyses tend to be highly research oriented. The lab uses the best available technology and many of their methods would not be suitable for high volumes or routine use. Time of analyses is generally not a factor and very long analyses times can occur. For example a counting time of several weeks can occur with some of the ETS samples.

Several methods used in characterizing or monitoring WSRC materials are performed by offsite laboratories and their procedures are not listed. Chemical analyses in support of site environmental monitoring (EM) are primarily done by offsite laboratories. Analyses for characterizing non-radioactive hazardous wastes are done by offsite laboratories. These laboratories are required to follow standard EPA methods with the exception that they may request a deviation from us. The lab must have approval by the state for deviations to a method. For the most part the offsite analytical laboratories closely follow the EPA method for NPDES requirements as these are the ones primarily checked by the state. The offsite laboratories are monitored with a blind sample compliance program and procedures for these operations are listed.

WSRC will also send samples to offsite laboratories for special analyse; such as corrosion testing or R\&D analyses by specialized laboratories. Those analytical methods are not listed.

cc:

L,M. Papouchado, 773A

C.E. Coffey, 773A

J.G. Donnan, 772-3F

J.D. Heffner, 735A

R.H. Young, 735-11A

K. Andringa, 773-41A

P.F. Cloessner, 773A

J.E. Young, 773A

A.R. Jurgensen, 773A

J.S. Roberts, 742A

W.R. Jacobsen, 772-3F

E.L. Graf, 704S

H.A. Helms, 704A

M.A. Ebra, 704H

B. D. Helton, 773-41A

J.T. Coleman, 773-41A

D. Hiland, 773-41A

G. Street, 773-41A

D. Plung, MSD Woodside

SRL RECORDS (4)

M.G. O'Rear, DOE-SR

P. Jenkins, DOE-SR

T. Dyches, DOE-SR

offsite: Daniel Lillian, DOE-LMB

Barry Lesnick, DOE-LMB

Don Bogen, DOE-EML. 
Tom Gesell, DOE-RESL

Stan Morton, DOE-RESL.

\section{FAST TEAM:}

Ernest Gladney, Los Alamos, HSE-9

Craig Leasure, Los Alamos HSE-9

Curtis Stroup, WHO

Peter Lindahl, Argonne

Jim Stokely, ORNL y 12

Roy Morrow, ORNL k25

Janine Arvizu, INEL

Steven Brown, INEL

Herbert Sutter, SAIC 


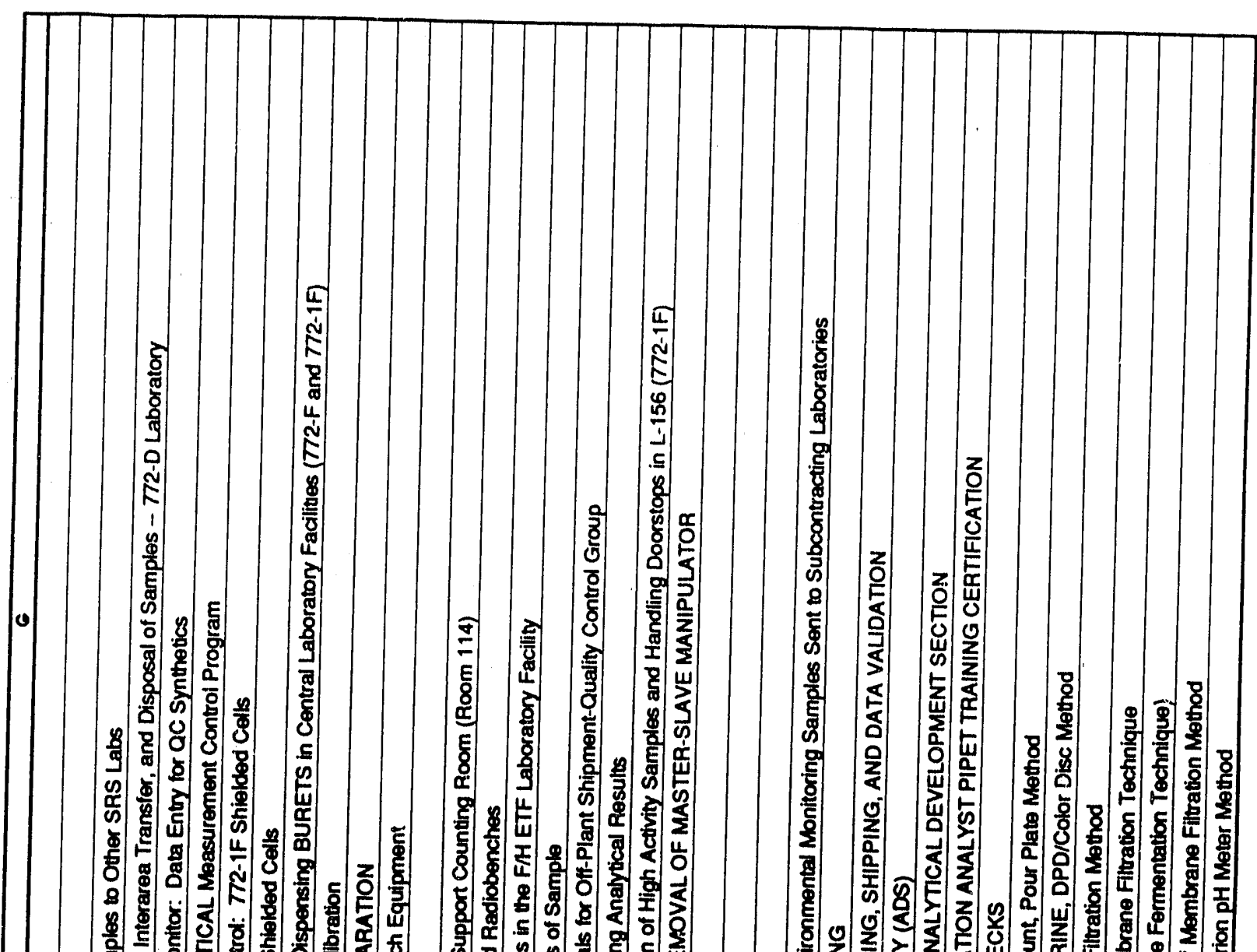

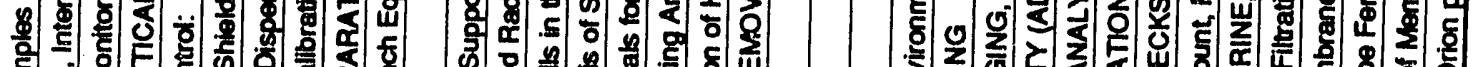

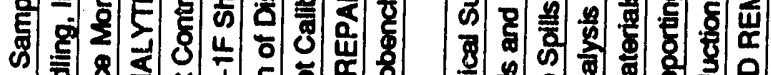

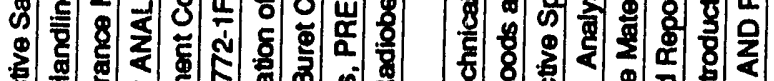

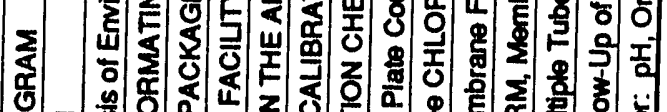
: क्ञ 兽

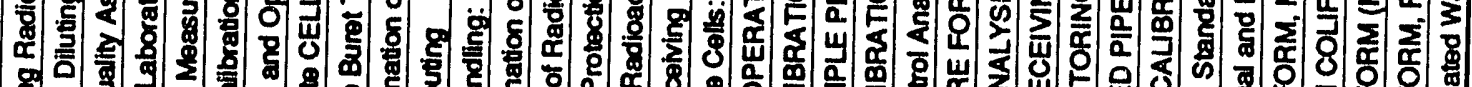

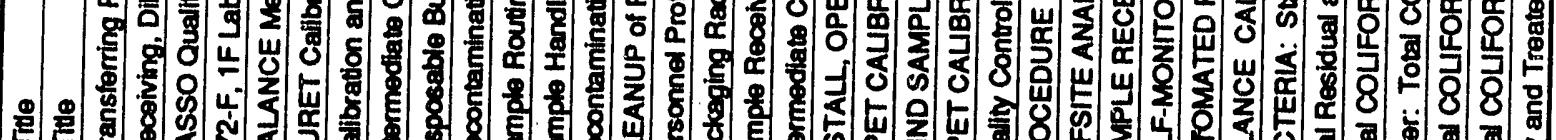

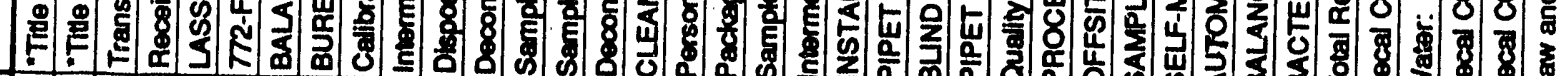
4 ¿

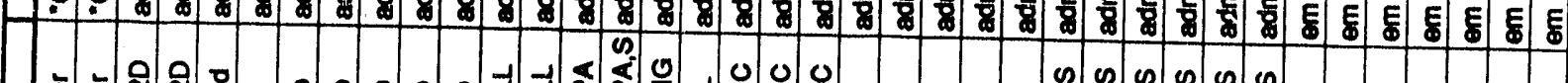

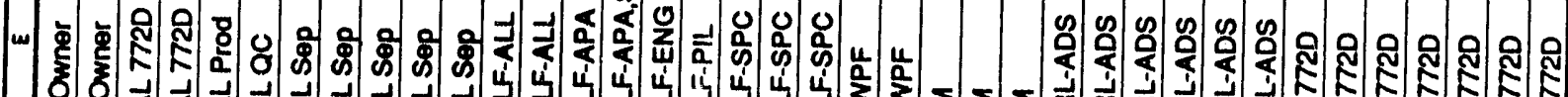
ô.

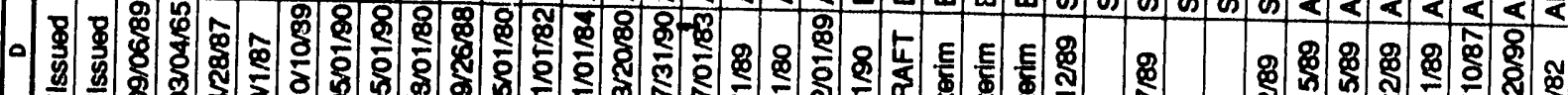

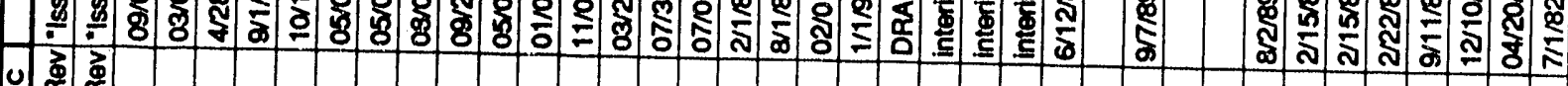

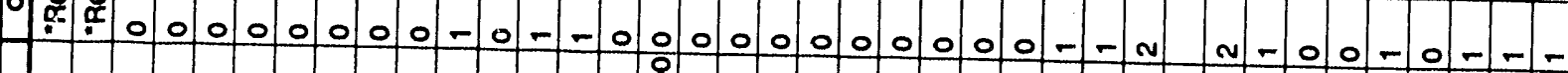

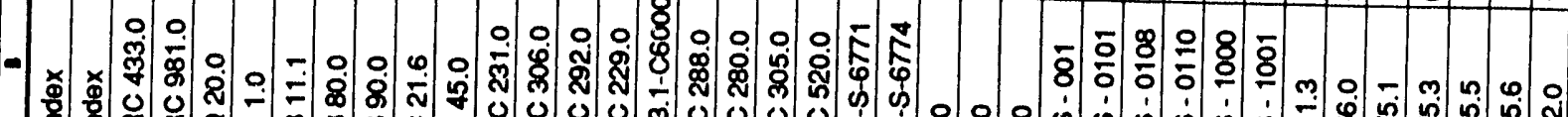
흘

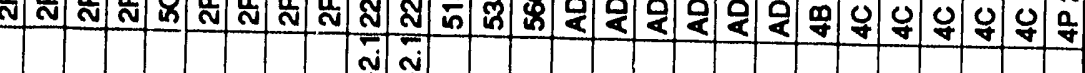

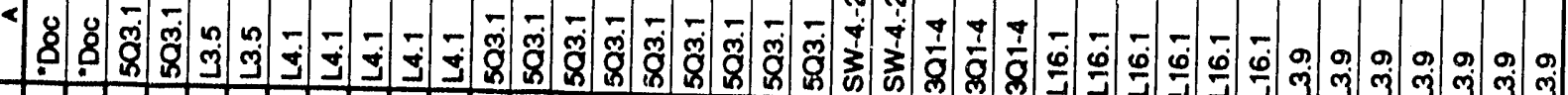




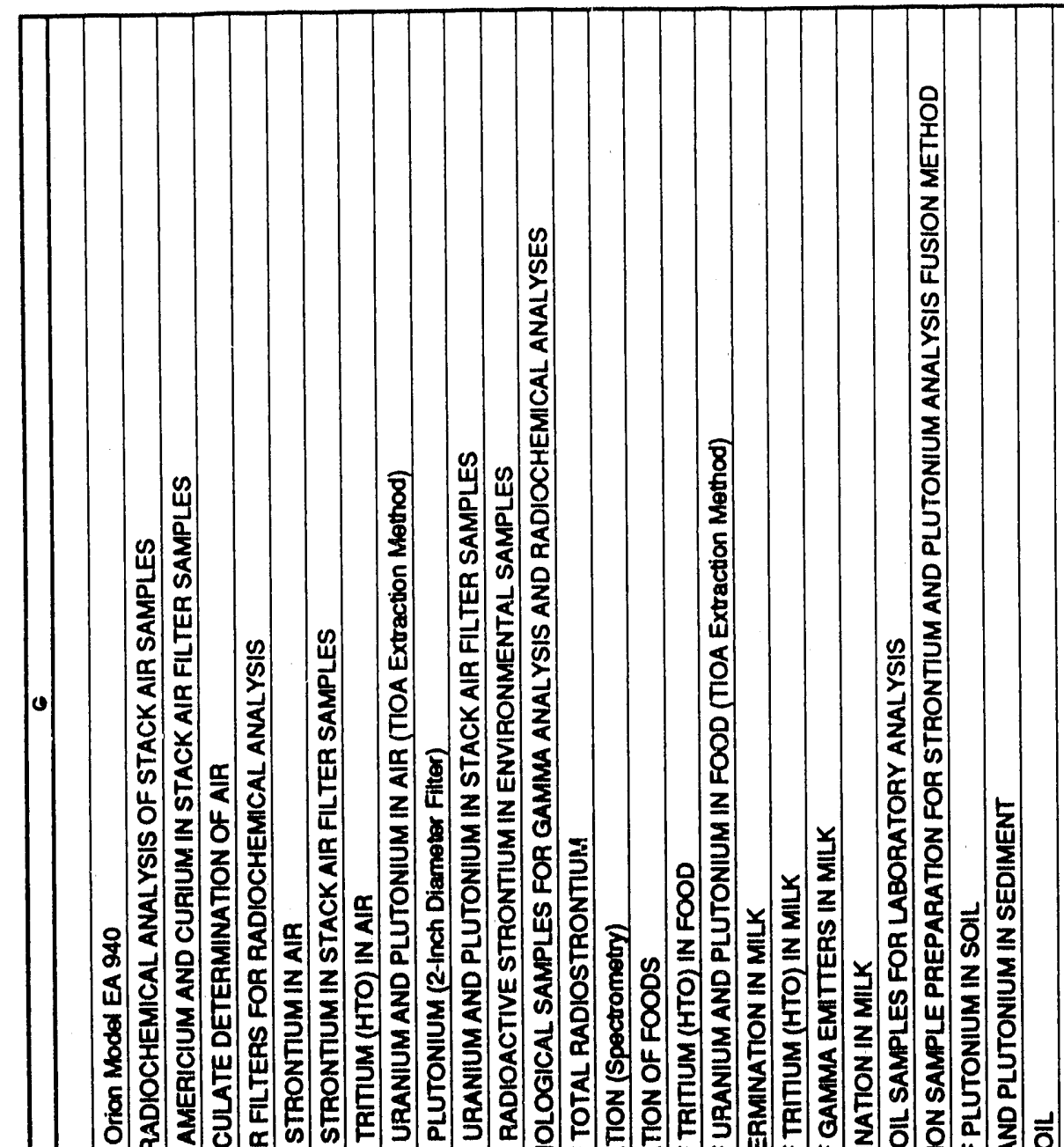

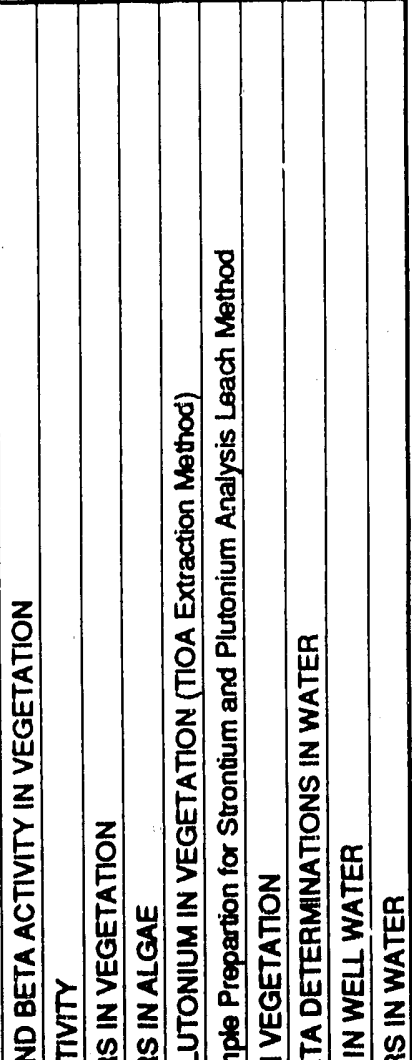

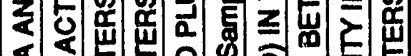

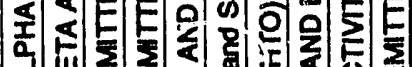
tit

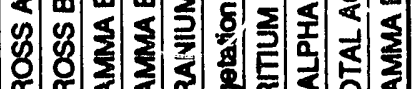

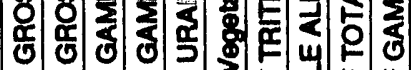
约ง

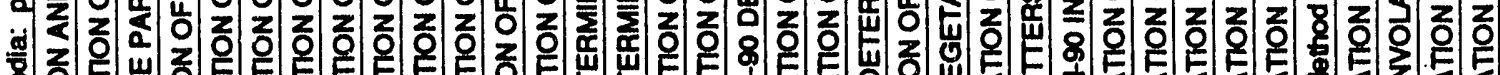

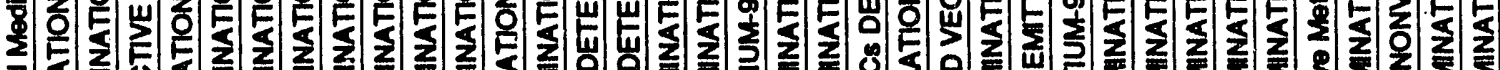
mat

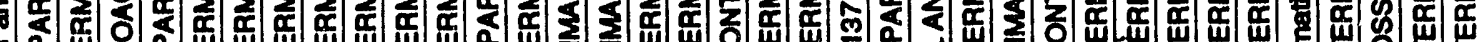

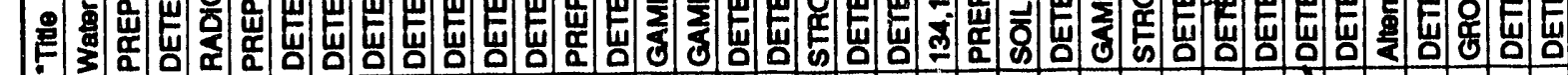

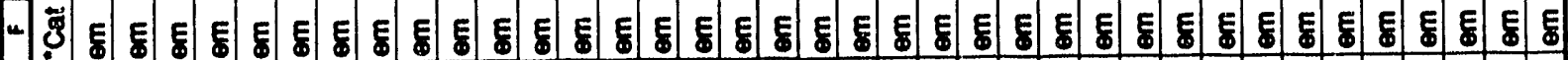
- 1 กิ

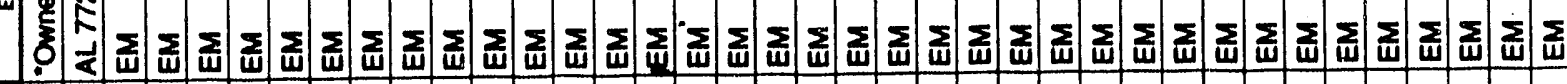

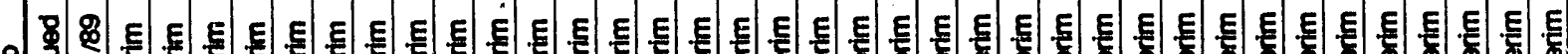
- 䝴

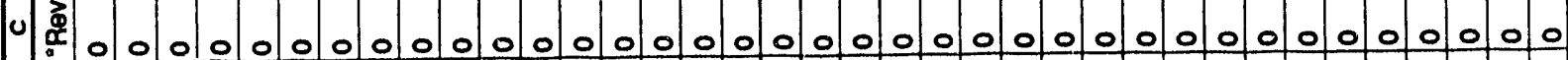

-

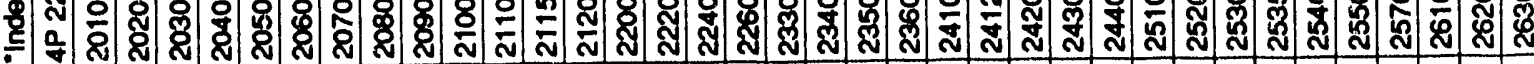

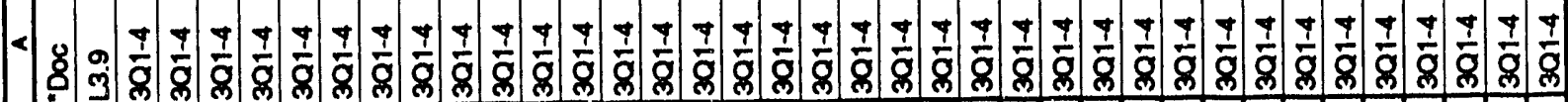

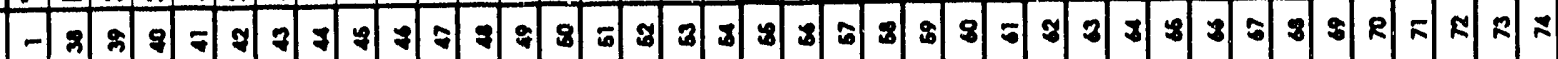




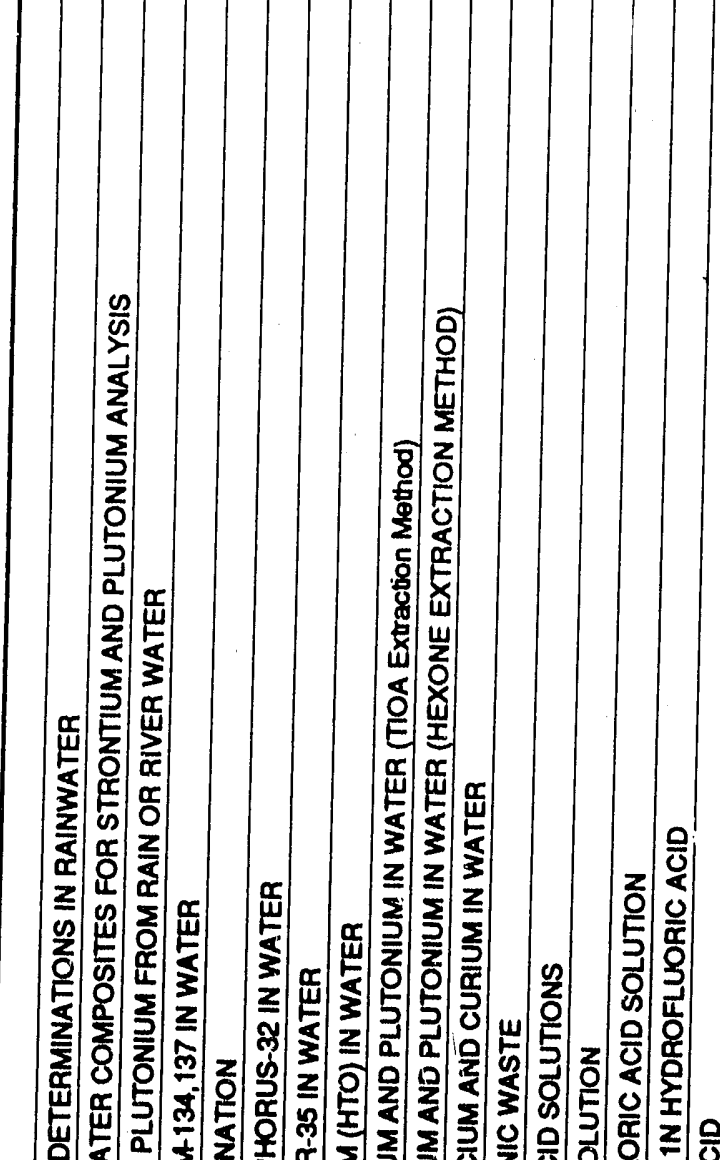

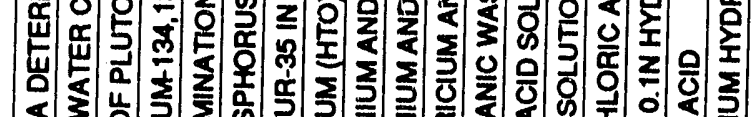

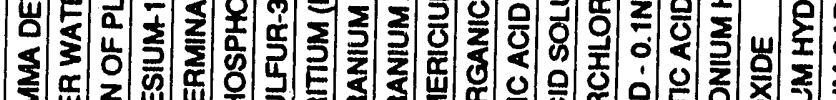

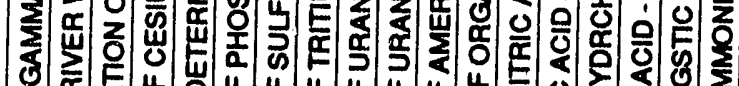

仓

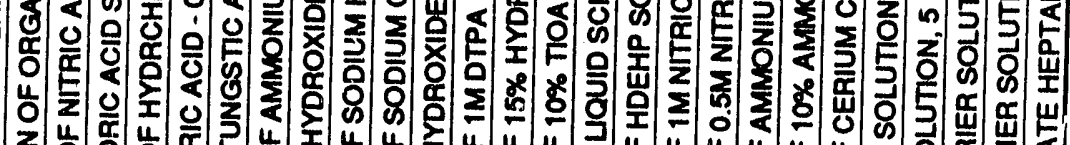
z

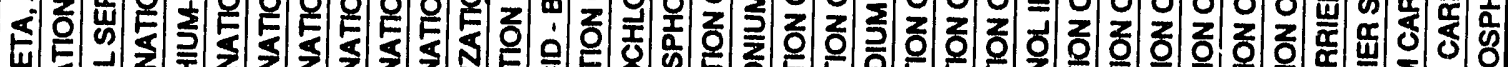

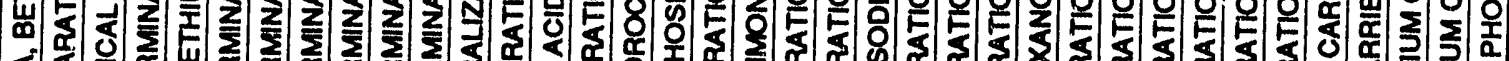

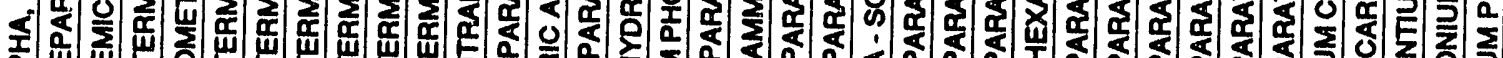

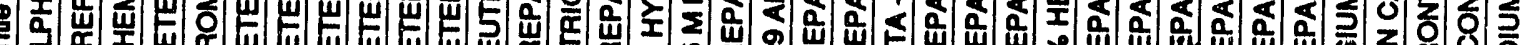

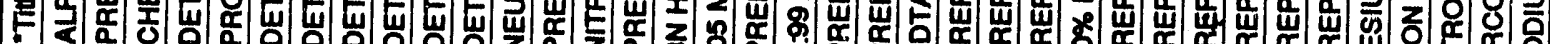

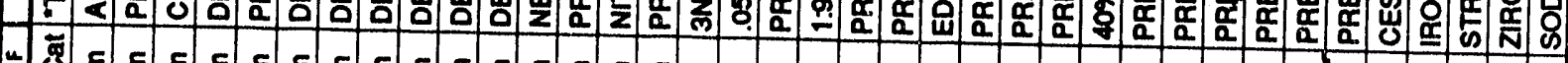

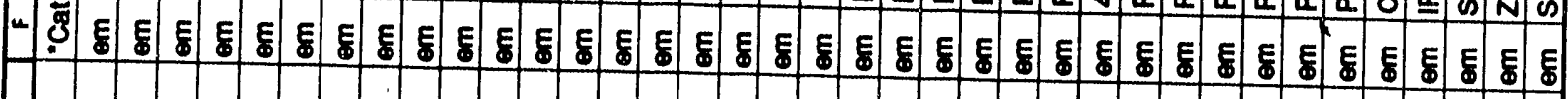
$\overline{\$}$

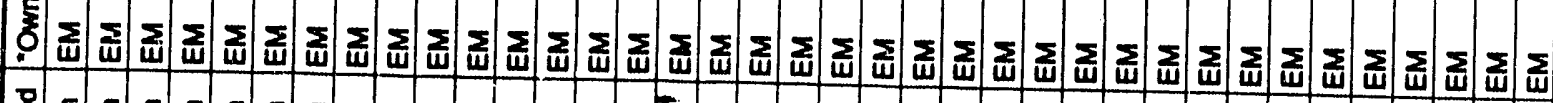

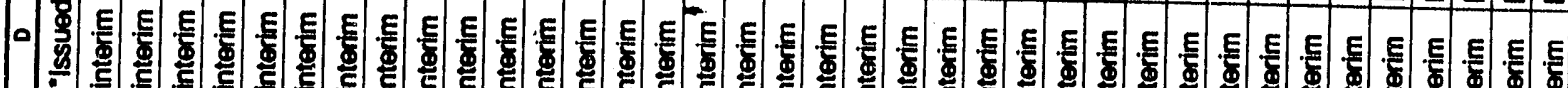

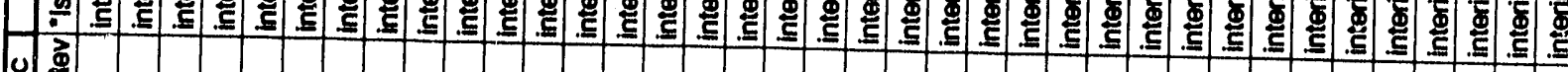
00 - o o o o o o o o o o o o o o o o o o o o o o -

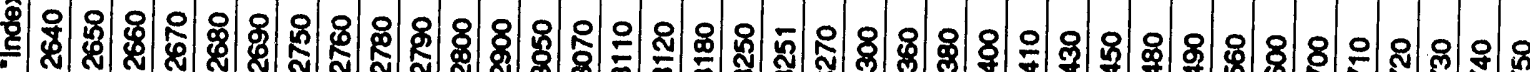

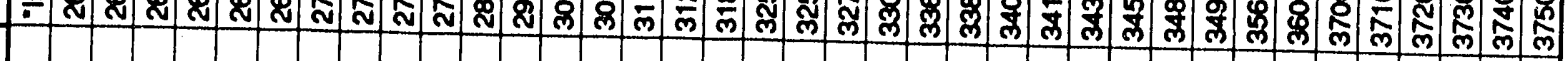

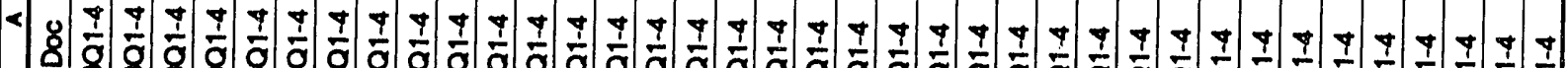

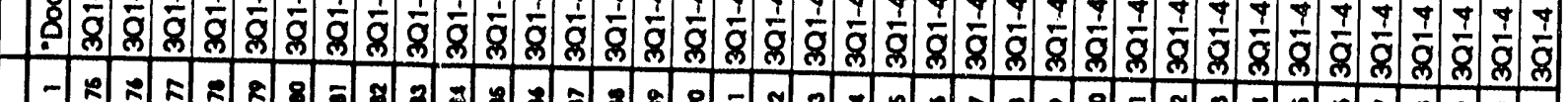




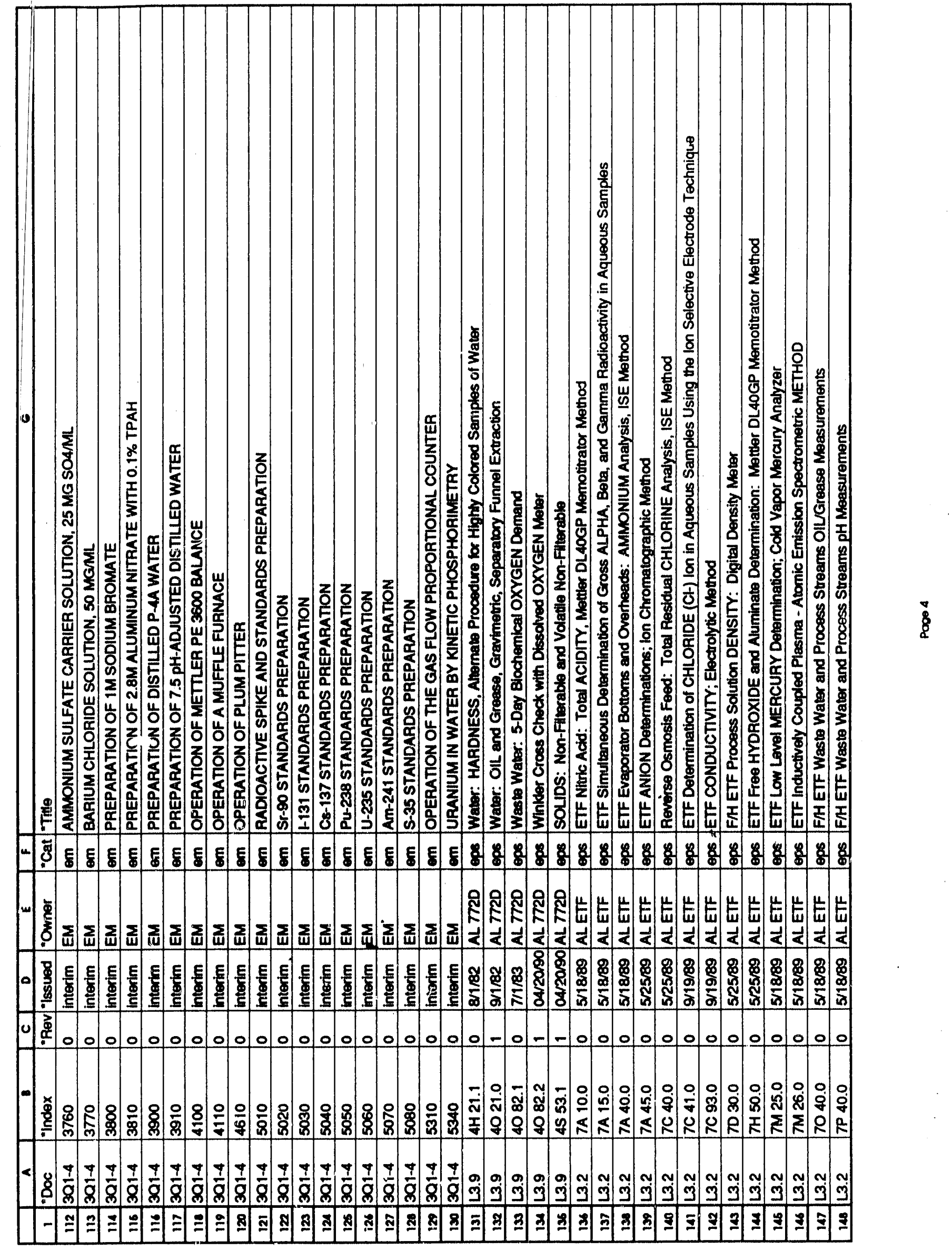




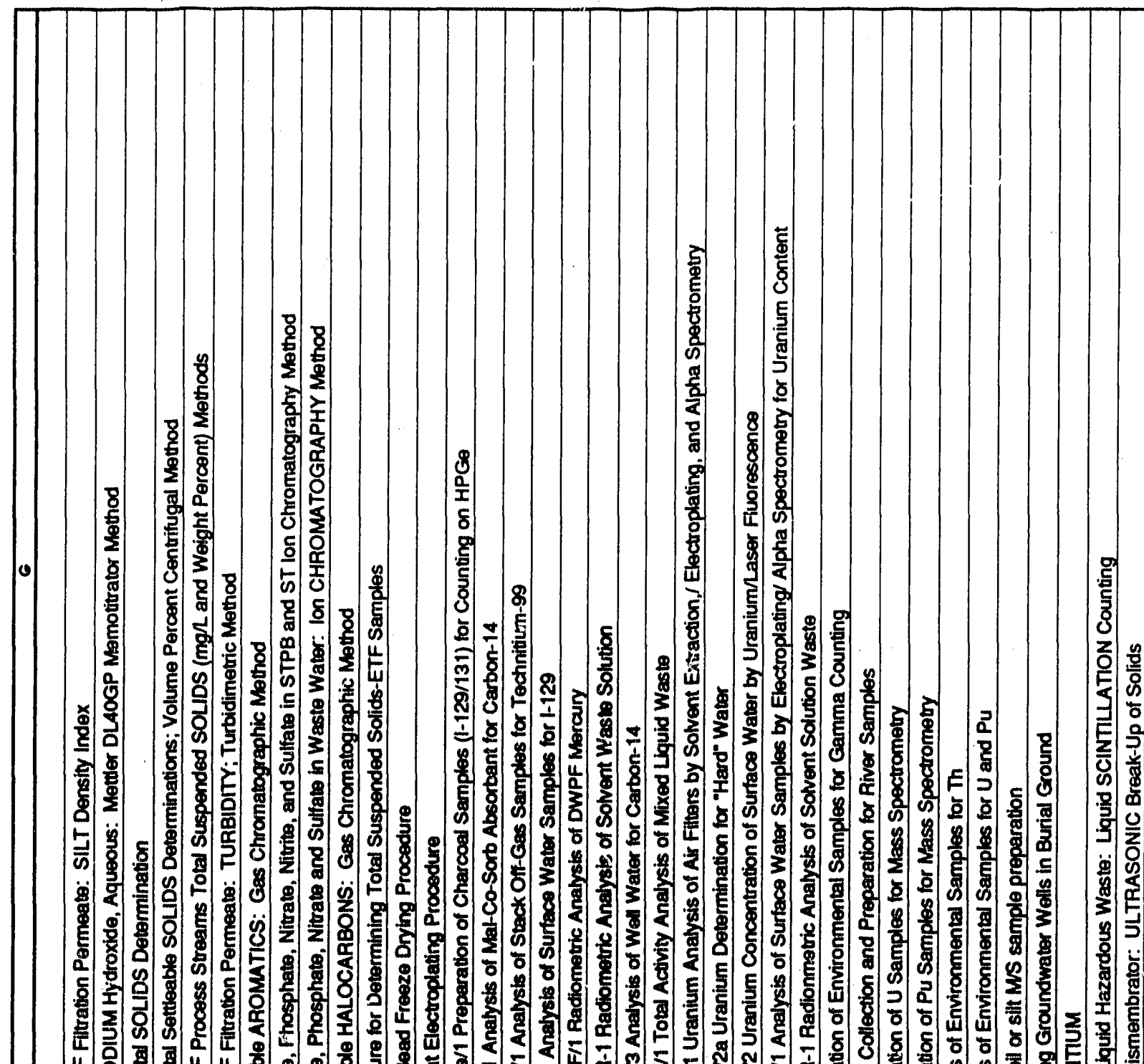

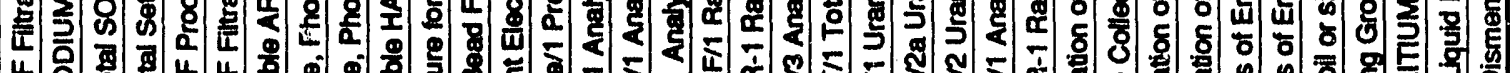
-

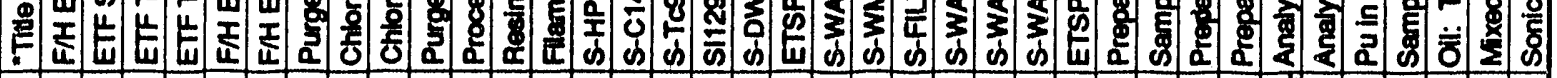

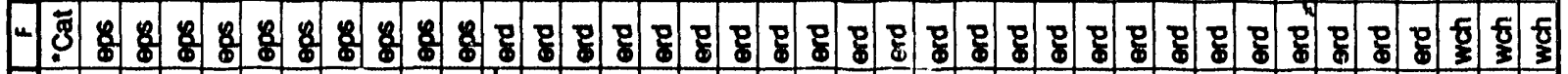
W

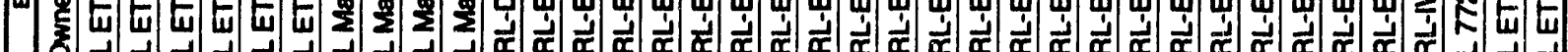

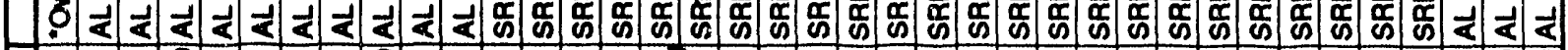

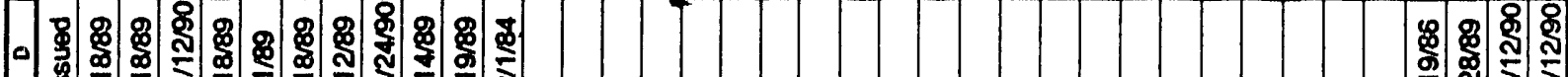

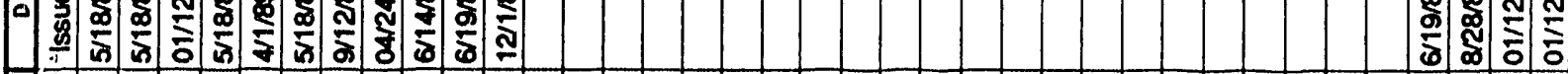

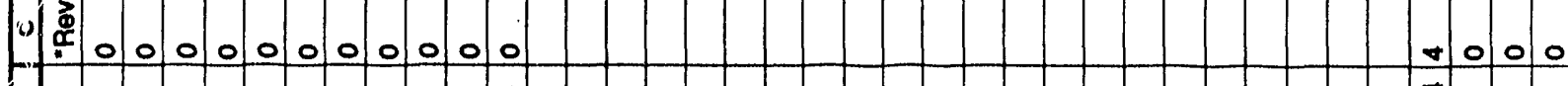

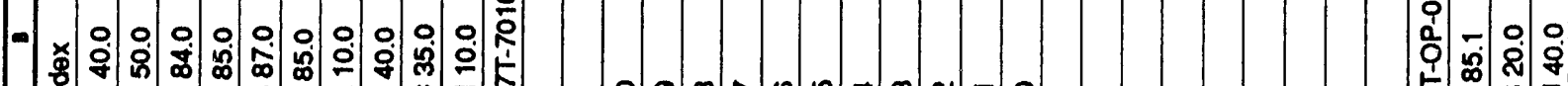

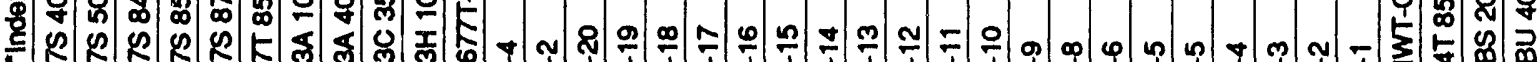

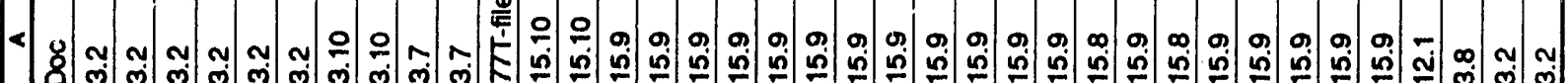

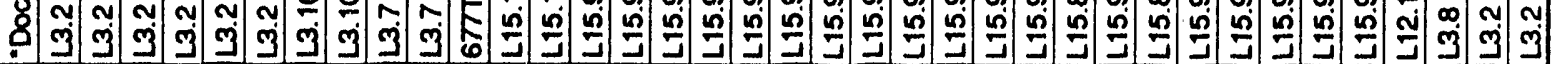
- 


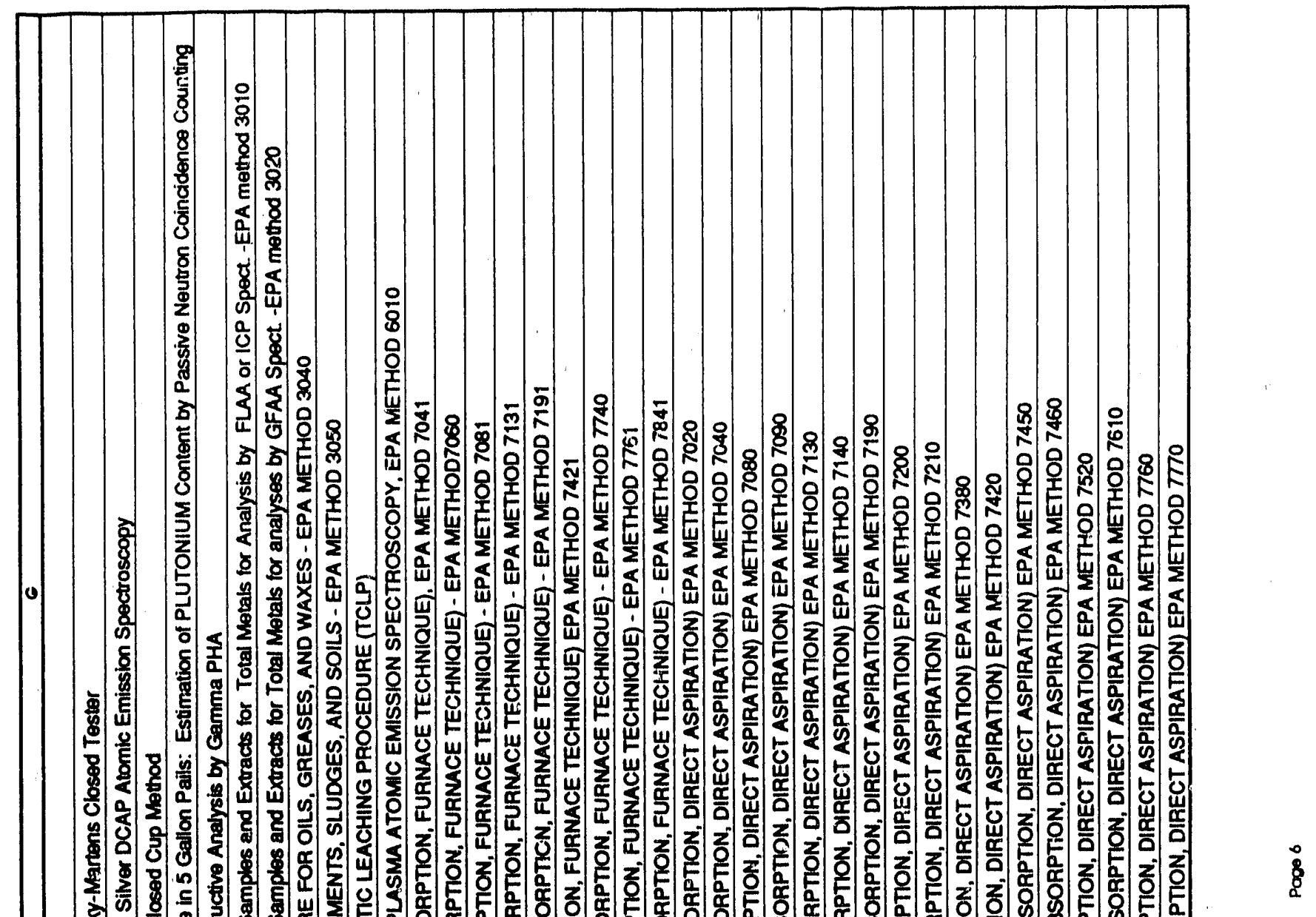
\%

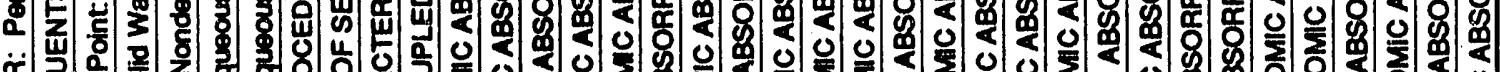
采

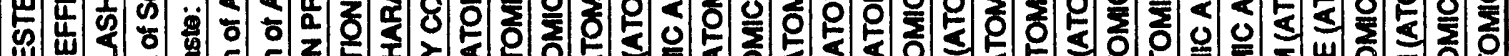

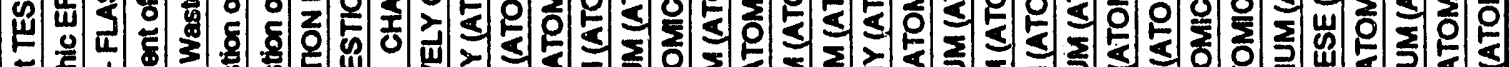
등

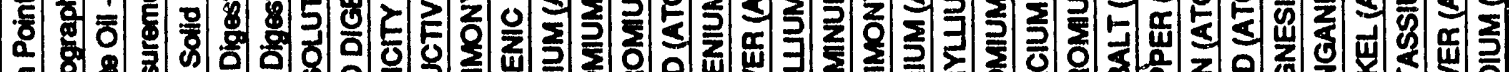
월 息

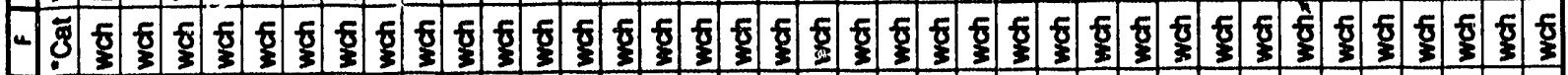
س

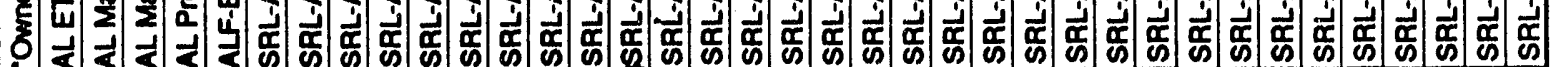
\$

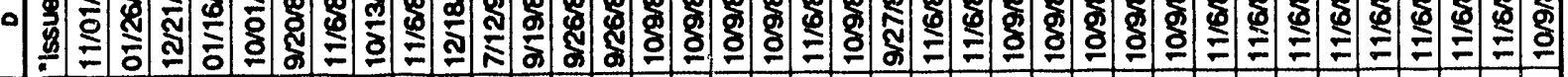
U

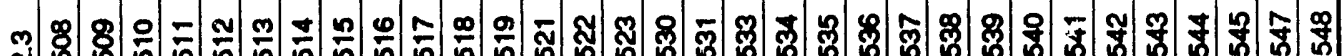

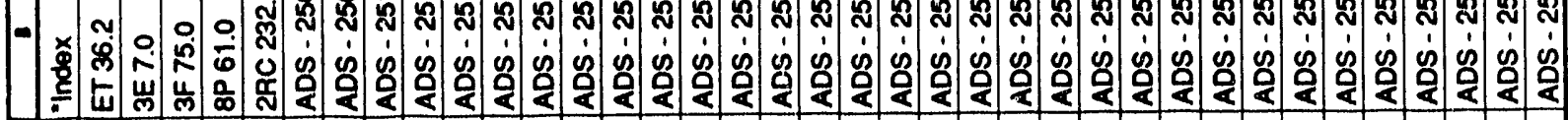

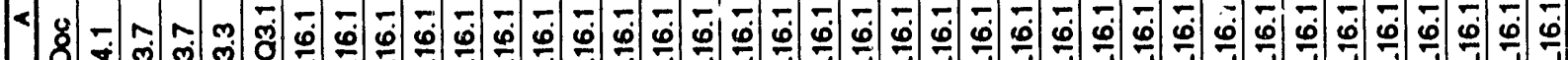

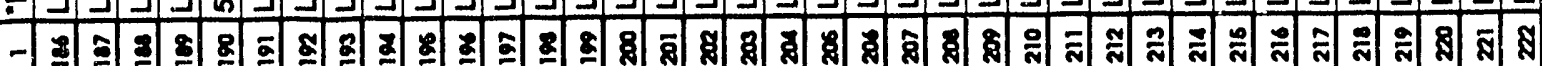




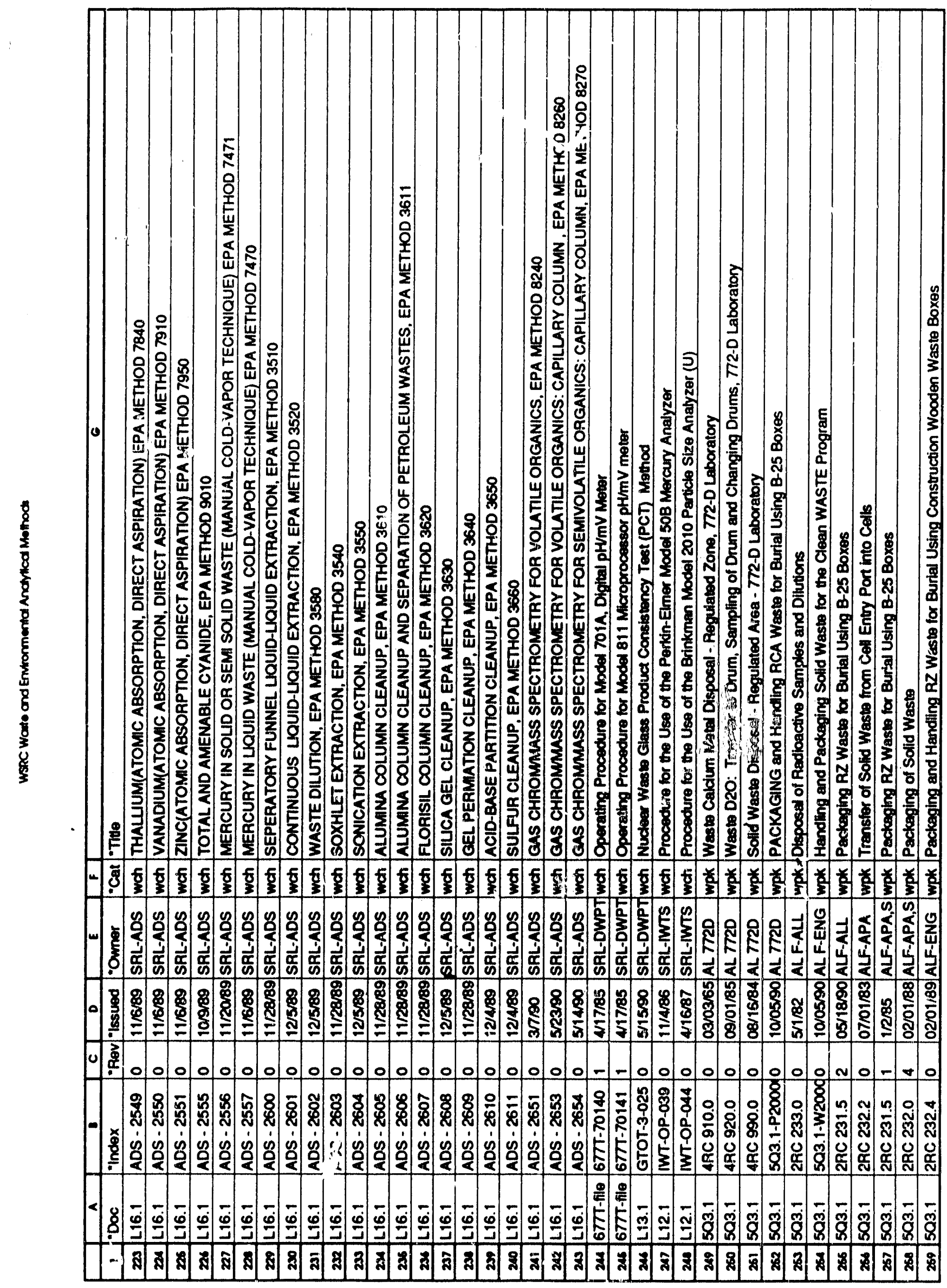




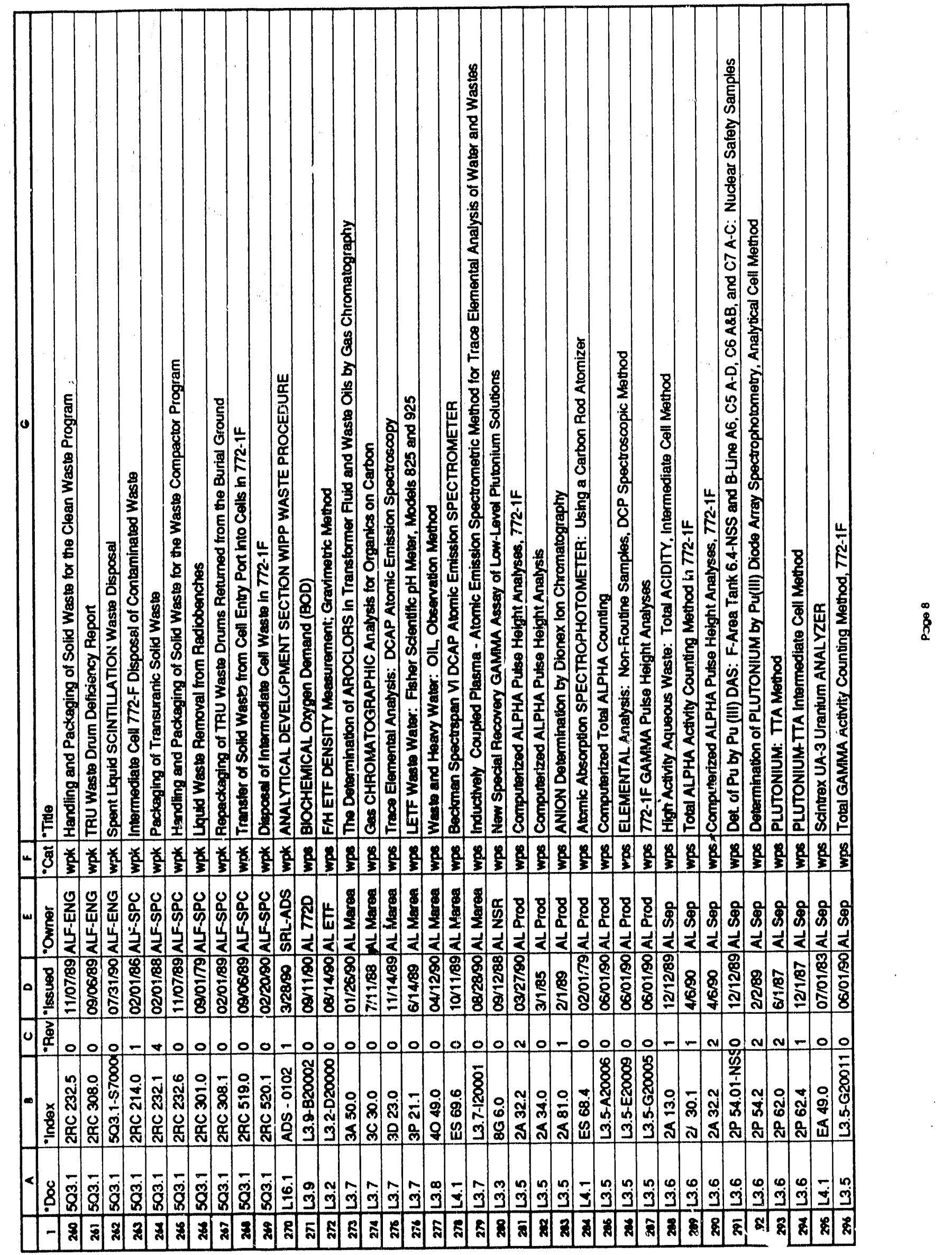




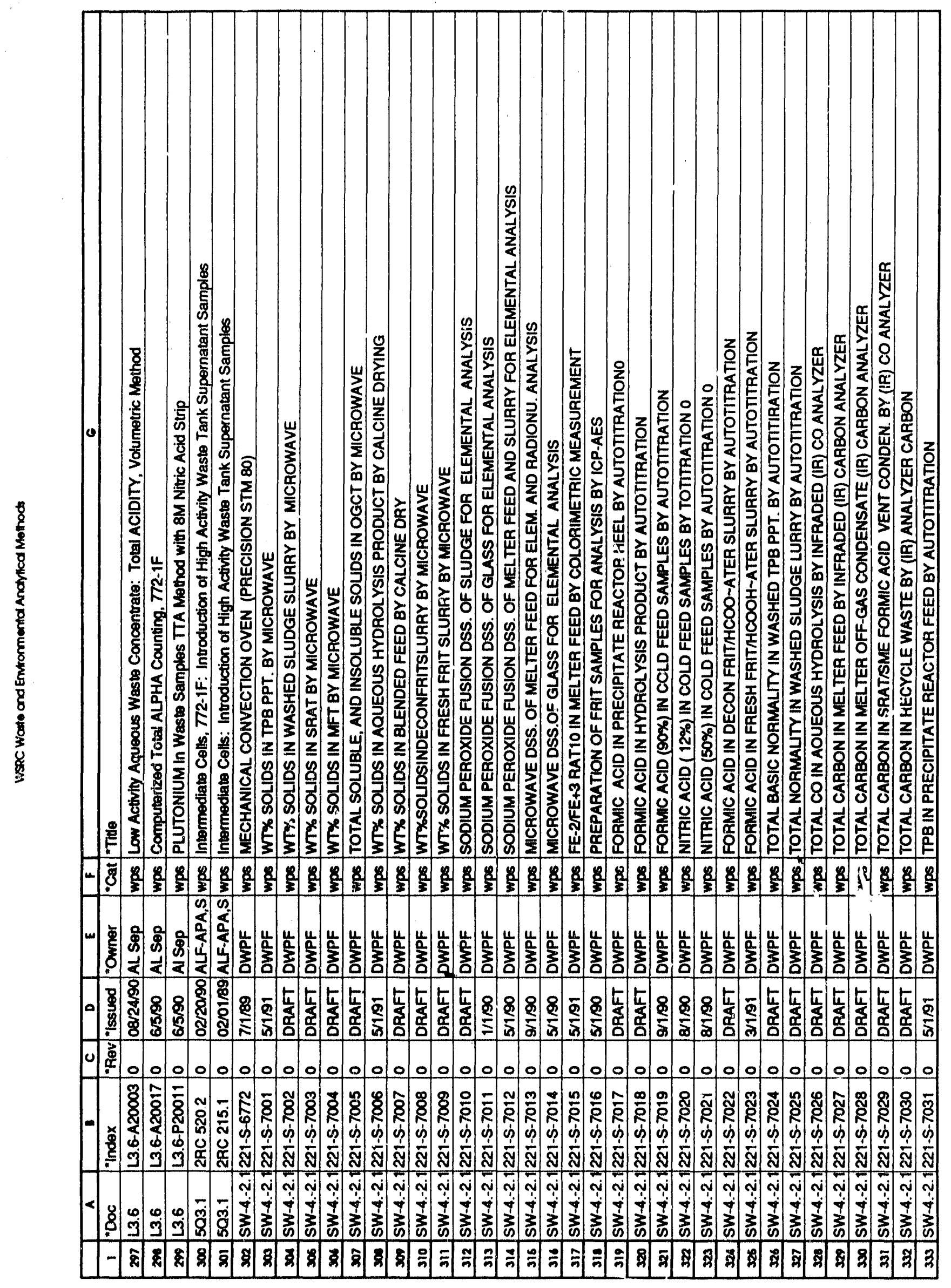




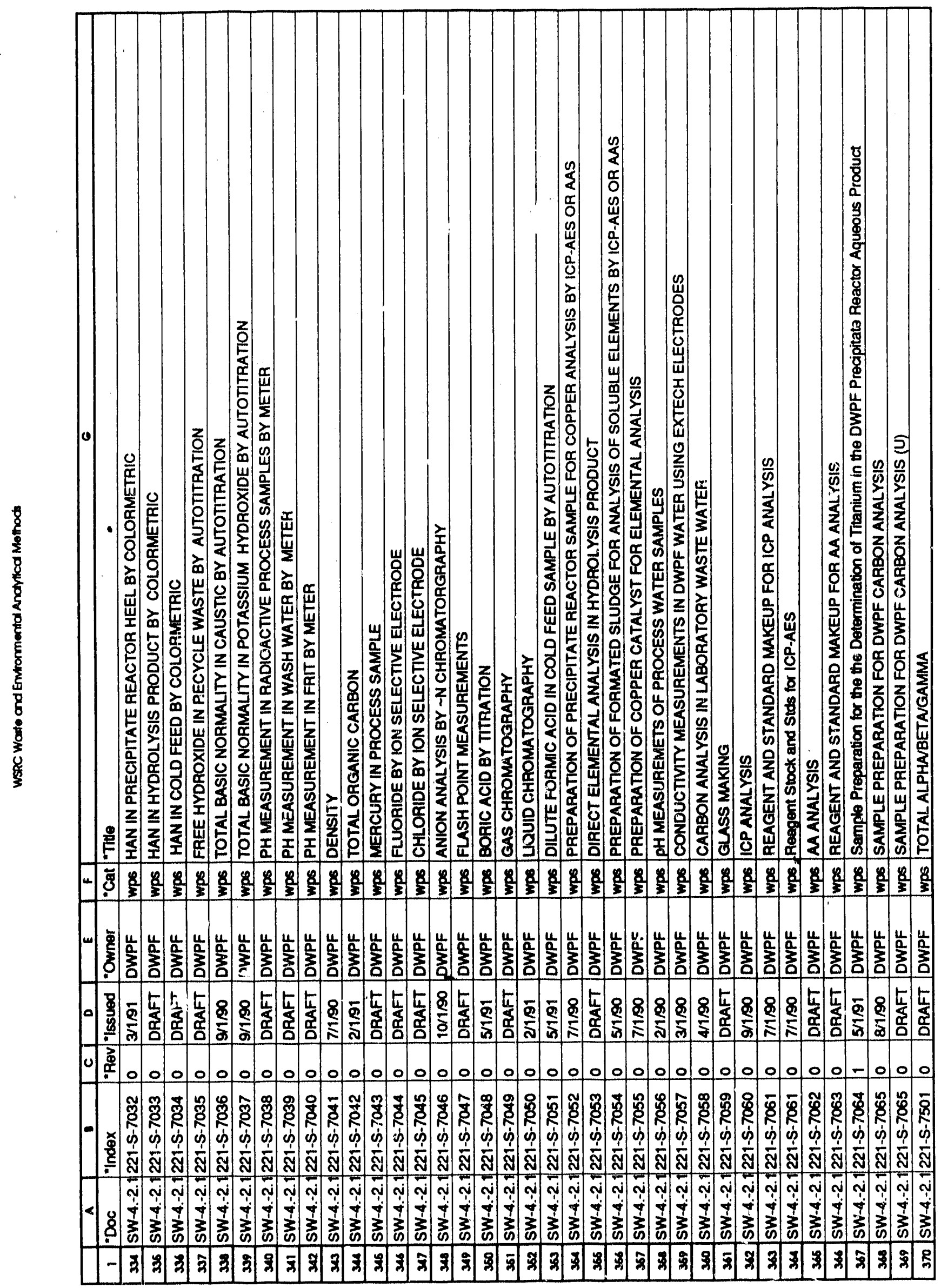




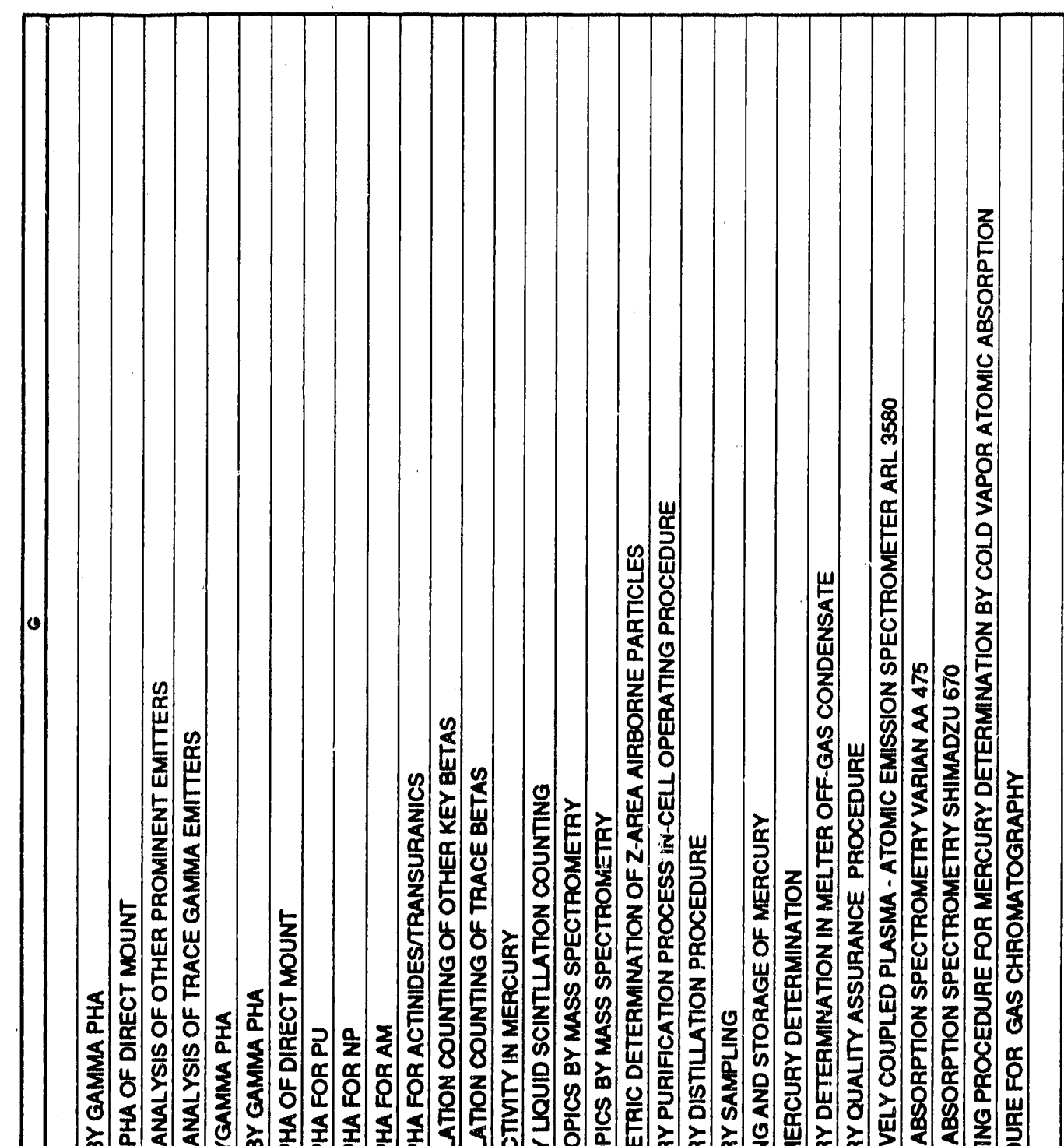

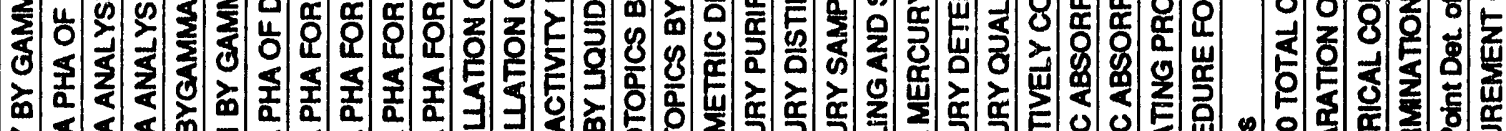

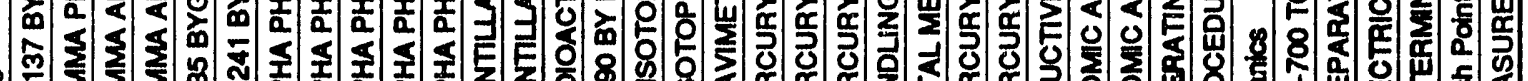

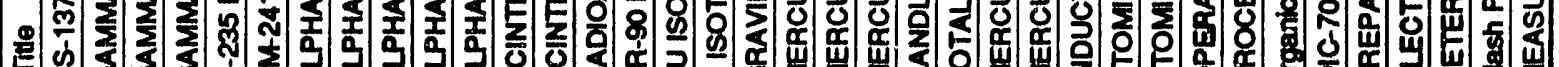

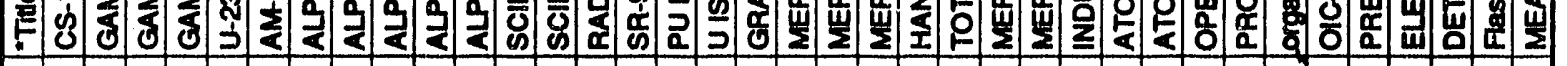

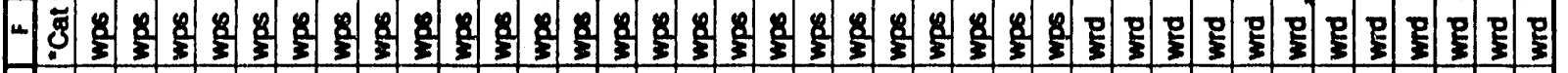

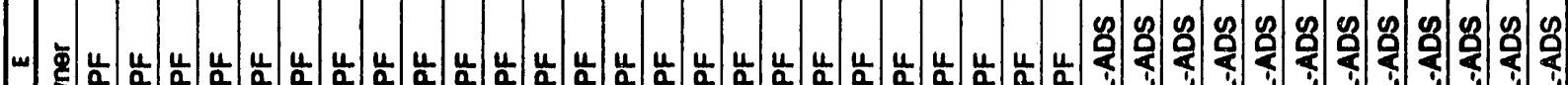

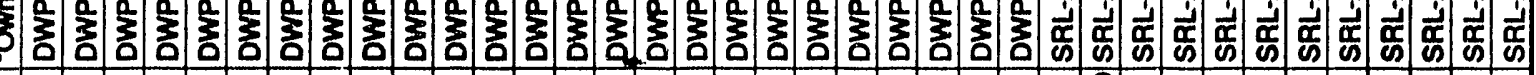

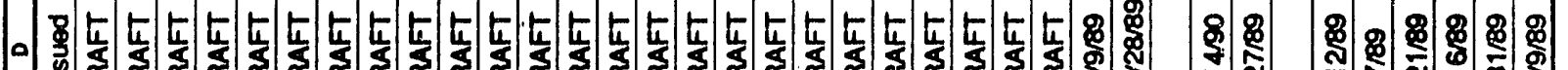

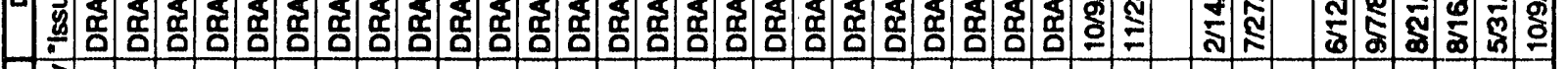

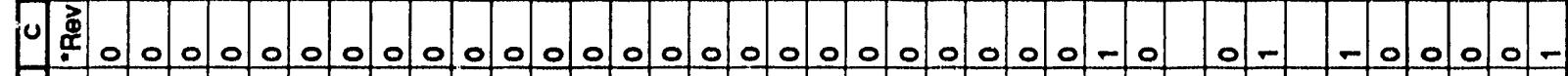
ก 는

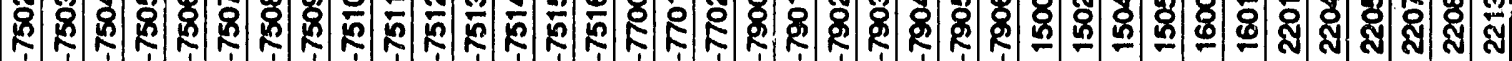

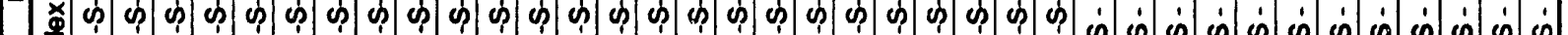

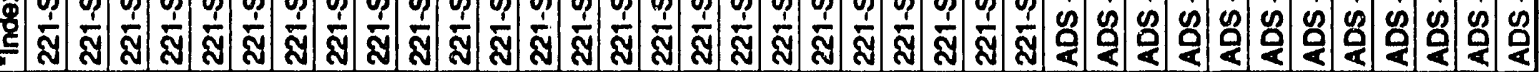

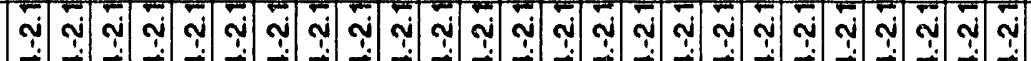

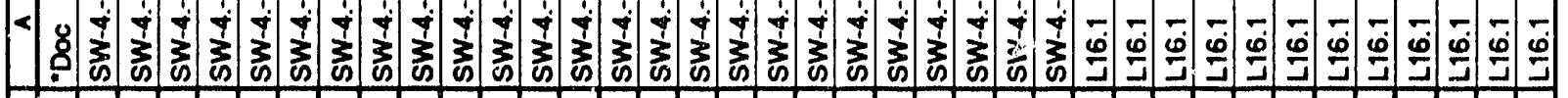

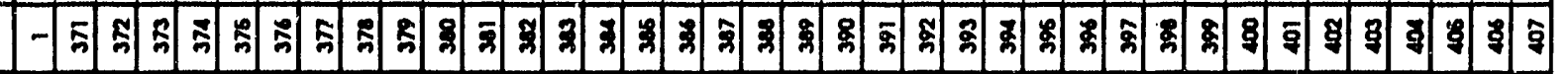




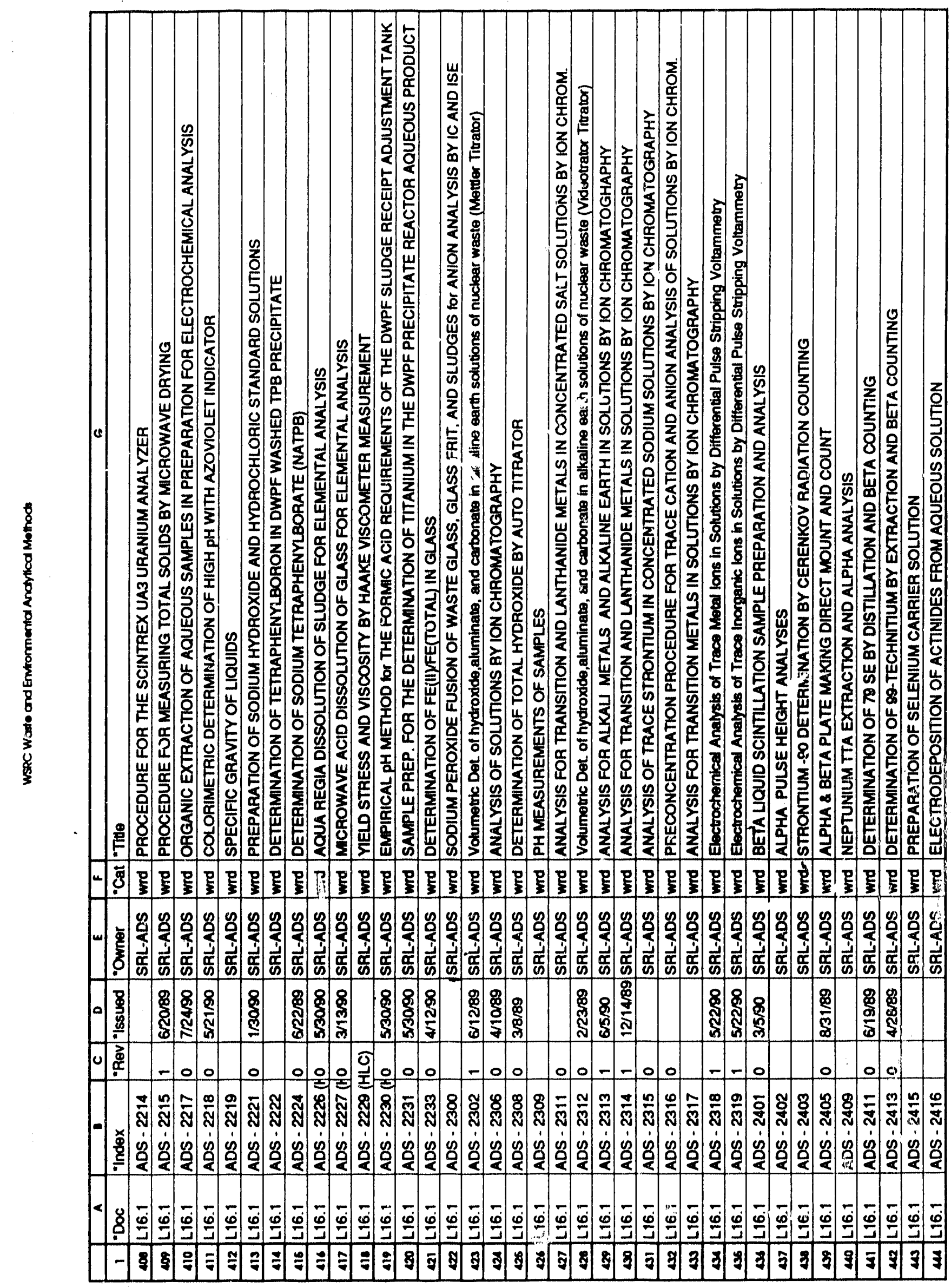




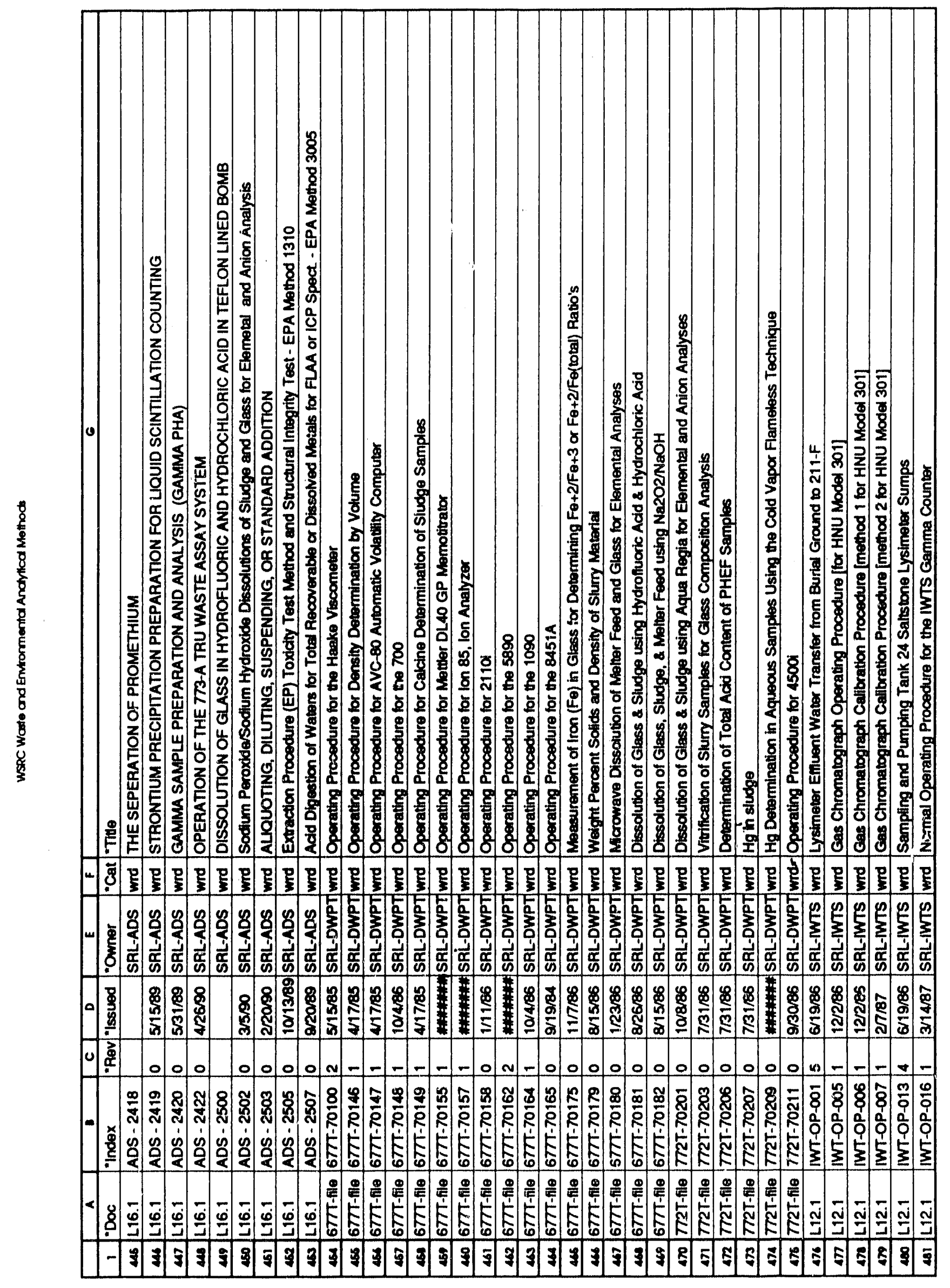




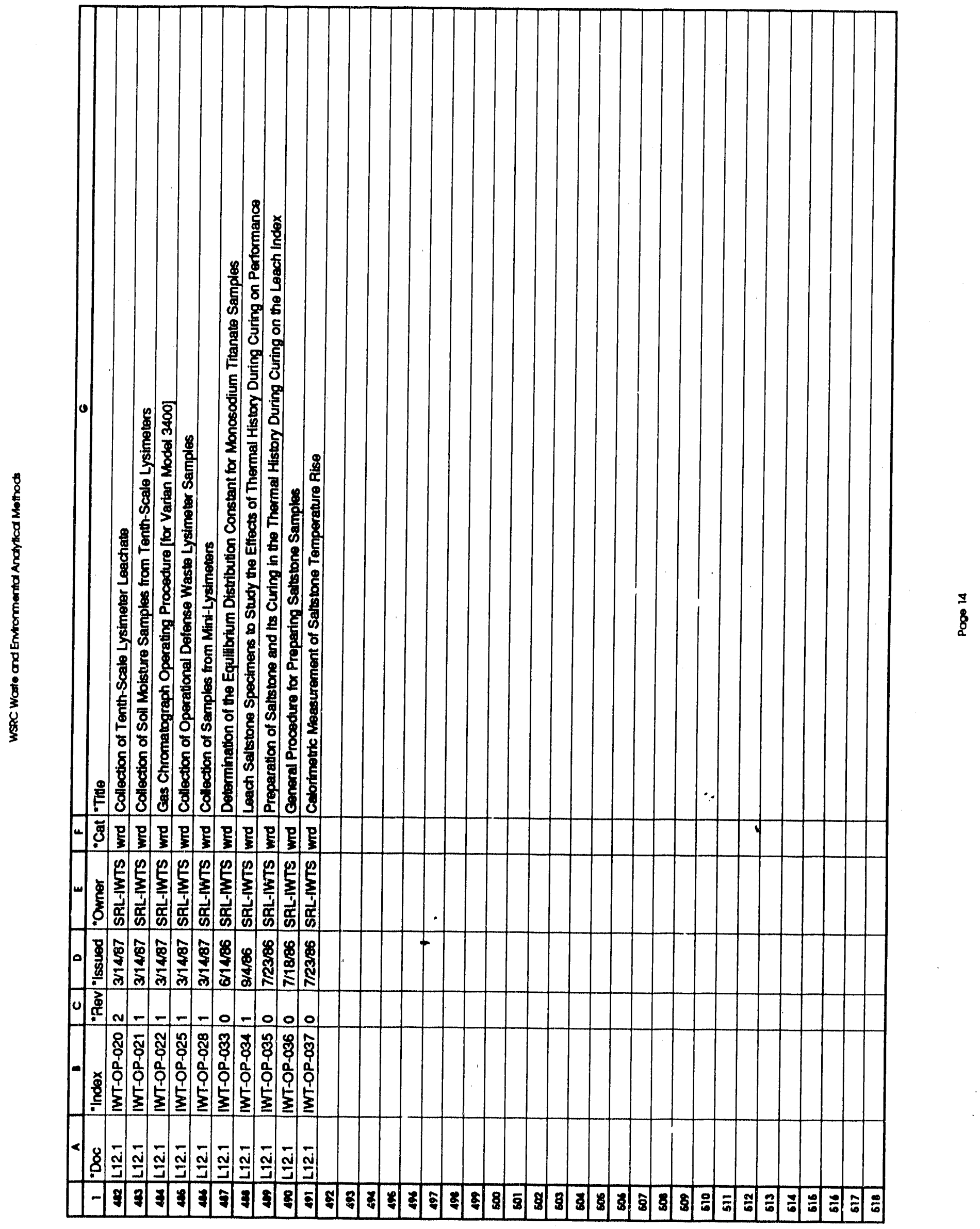



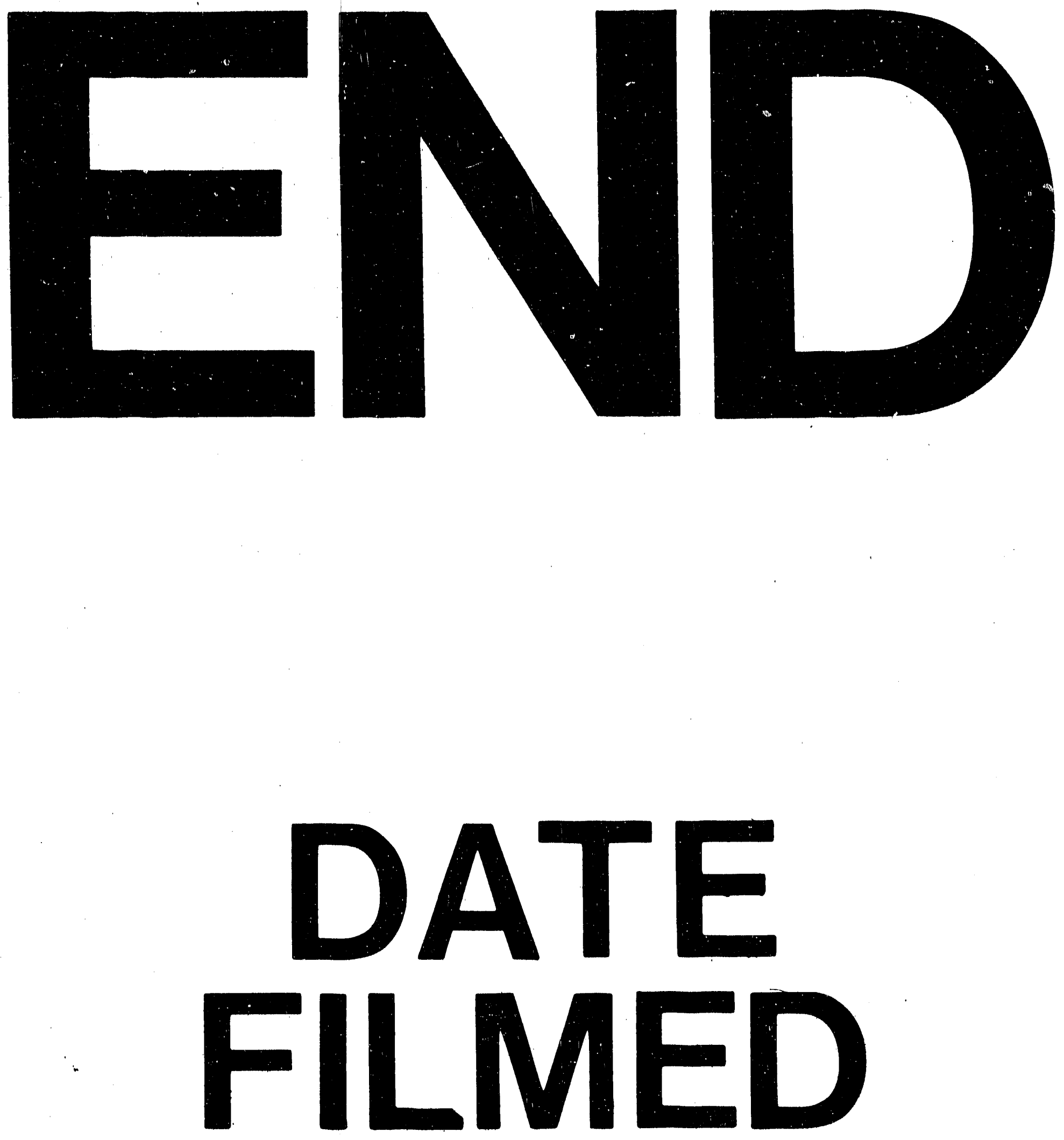

I

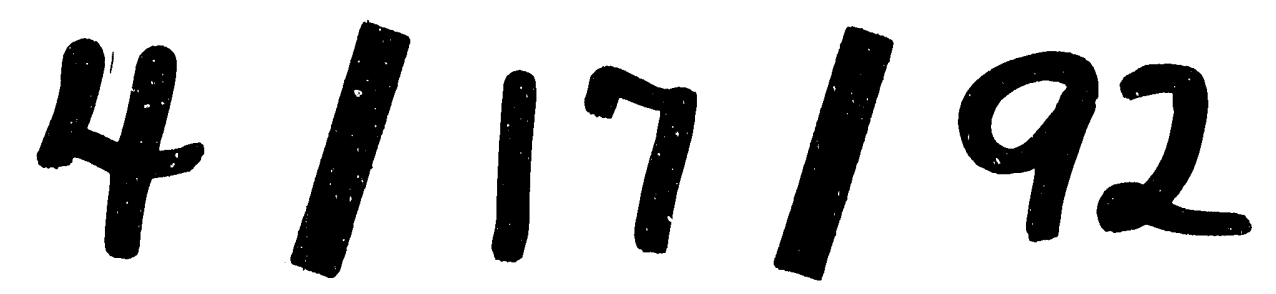


